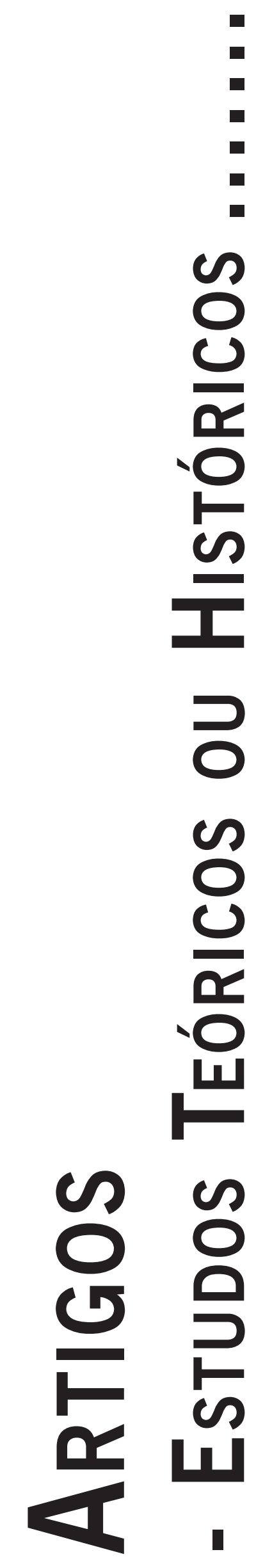




\title{
OS VALORES E A SUA IMPORTÂNCIA PARA A TEORIA DA CLÍNICA DA ABORDAGEM CENTRADA NA PESSOA
}

\author{
Values and their Importance for Clinical Theory of the Person-Centered Approach \\ Los Valores y su Importancia para la Teoría de la Clínica en el Enfoque Centrado en la Persona \\ Iago Cavalcante Araújo \\ José CÉLIO FreIRE
}

\begin{abstract}
Resumo: A Abordagem Centrada na Pessoa (ACP), assim como qualquer atividade humana, está fundamentada sobre alguns valores, entre os quais o valor da pessoa. Por um lado, a abordagem prevê uma prática profissional em que o psicólogo seja íntegro na sua relação com o cliente, portando valores, sentimentos e percepções. Por outro, entendemos que tais valores pessoais não devem ser passados ao cliente, pois assim estaríamos arriscando a sua autonomia e nos contradizendo com o processo valorativo organísmico proposto por Carl Rogers. Nosso trabalho discute o lugar dos valores pessoais do psicólogo na teoria da clínica da ACP. Compreendemos que a psicoterapia rogeriana é um processo de aprendizagem significativa de valores, o que não implica em um ensino de tais valores por parte do psicólogo. Entre outros aspectos, entendemos que seja necessária uma maior apropriação dos valores da Abordagem Centrada na Pessoa pelos profissionais, além da promoção de ambientes e produções que tratem dos aspectos éticos da sua prática.
\end{abstract}

Palavras-chave: valores pessoais; psicologia clínica; abordagem centrada na pessoa; ética.

\begin{abstract}
The Person-Centered Approach (PCA), as well as any human activity, is based on certain values, and among them, is a person's worth. On the one hand, the approach consists of a professional practice in which the psychologist, bearing their own values, feelings, and perceptions, acts with integrity towards the client. On the other hand, we understand that such personal values should not be passed on to the client, or else we would be risking their autonomy and contradicting the organismic valuing process, as proposed by Carl Rogers. This essay discusses the place of clinical psychologists' personal values in the PCA clinical theory. We understand that Rogerian psychotherapy is a process in which values are learned, which does not necessarily mean psychologists will teach such values. Among other aspects, we understand that professionals who use PersonCentered Approach need to further acquire its values, as well promote environments and productions that address the ethical aspects of its practice.

Keywords: personal values; clinical psychology; person-centered approach; ethics.

Resumen: El Enfoque Centrado en la Persona (ECP), así como cualquier actividad humana, se basa en ciertos valores, de los cuales se destaca el valor de la persona. Por un lado, el enfoque ofrece una práctica profesional en la que el psicólogo se muestra sencillo en su relación con el cliente, con valores, sentimientos y percepciones. Por otro lado, entendemos que estos valores personales no deben ser pasados a los clientes, así se pondría en riesgo su autonomía y en contradicción el proceso evaluativo organísmico propuesto por Carl Rogers. Nuestro trabajo discute el lugar de los valores personales del psicólogo clínico en la teoría del ECP. Entendemos que la psicoterapia de Rogers es un proceso de aprendizaje significativo de los valores, lo cual no implica una enseñanza de esos valores por el psicólogo. Entre otros aspectos, entendemos la necesidad de una mayor apropiación de los valores del ECP por los profesionales, además de promover ambientes y producciones que aborden los aspectos éticos de su práctica. Palabras clave: valores personales; psicología clínica; enfoque centrado en la persona; ética.
\end{abstract}

\section{Introdução}

A prática da psicoterapia, como qualquer outra profissão, principalmente as que lidam com seres humanos, requer dois tipos de competência: uma proveniente de uma formação especial e outra advinda de atributos pessoais. Entretanto, diferentemente das demais profissões, na prática clínica psicológica, segundo Kinget (1959/1977), "quanto mais a experiência cresce neste campo, mais a importância da personalidade do terapeuta parece impor-se sobre sua formação profissional" (p. 101), o que não implica em um declínio do seu interesse pela formação. Para Moreira (2009), uma das grandes características de nossa atuação clínica psicoterápica é a solidão, pois, a portas fechadas, o psicólogo está diante da imprevisibilidade e da alteridade do sujeito. Neste momento, as técnicas podem oferecer segurança, no entanto, não serão capaz de totalizar e enquadrar a situação por completo. Para Rogers (1967/1991), a longo prazo, a qualidade do encontro era mais importante do que a formação teórica, preparo profissional e técnicas psicológicas. 
Sobre a Abordagem Centrada na Pessoa (ACP), na qual está inserida a Terapia Centrada na Pessoa (TCC), Amatuzzi (2010) afirma que, "em última instância, ela não se justifica como uma técnica e sim, como uma ética: uma ética das relações humanas (interpessoais, comunitárias, sociais, políticas). Justificar a ACP é explicitar e fundamentar, no plano teórico, os valores que ela expressa” (p. 23). Preocupando-se com a fundamentação de uma prática clínica que trabalhe a partir de um referencial de valores, Rogers (1967/1991) questiona:

(...) o cliente apenas adota o sistema de valores do terapeuta? será a terapia apenas uma recurso através do qual os valores não reconhecidos e não examinados do terapeuta se transmitem, sem que o saiba, a um cliente desprevenido? Este deve tornar-se o padre moderno, defendendo e revelando um sistema de valores ajustado aos dias atuais? E que sistema de valores seria esse? (p.14).

Sem lançar respostas, de imediato, à questão, Rogers passa a falar de um processo de valoração pautado na experiência organísmica, onde ele trata os valores como uma "tendência de todo ser vivo para mostrar preferência, em suas ações, por um tipo de objeto ou objetivo, em vez de outro" (p. 15); a isso ele denomina valor operativo. Desta forma, Rogers parece destacar que, em sua atuação, o psicólogo deve trabalhar somente com este tipo de valores, vinculados à própria experiência, e evitar, ao máximo, a "utilização" de valores concebidos. Esta última classe de valores diz respeito àqueles que foram aprendidos e “introjetados" e que são, em sua maioria, alheios à experiência. Ao expressar este tipo de valores, o psicólogo parte de um referencial outro que não o do cliente ou o da experiência da relação para direcionar a sua atuação, quando, na verdade, ao psicólogo rogeriano, caberia possibilitar ao cliente uma vivência de valorização apoiada na própria experiência.

É com o objetivo de fomentar o desenvolvimento e a integração do cliente que o psicólogo rogeriano deve promover uma atmosfera de acolhimento, compreensão e calor humano. Este objetivo deve ser, então, alcançado por meio de atitudes que Rogers (1957/1992) denominou de atitudes facilitadoras: a autenticidade, a consideração positiva e a empatia. Tais atitudes fazem parte de seis condições que elencou serem necessárias e suficientes para as transformações psicoterapêuticas. Entretanto, o próprio Rogers (2008) comenta a dificuldade de manter tais atitudes em todos os instantes da psicoterapia, mas, segundo ele, somente a tentativa de praticá-las já seria o bastante para promover uma mudança de personalidade: “(...) o que me impressiona é que mesmo tentativas imperfeitas de criar um clima de liberdade e aceitação e entendimento parecem liberar a pessoa para mover-se em direção a alvos sociais” (p. 123). Essas atitudes já foram tratadas e desenvolvidas de forma exaustiva por di- versos teóricos da ACP, portanto, daremos ênfase, aqui, ao caráter valorativo de cada uma delas. Nosso intuito é demonstrar como os valores se inserem na teoria da clínica apontada por Carl Rogers, tratando, a princípio, como ocorre esse processo de valoração, para, então, fundamentar a abordagem centrada na pessoa como uma prática de valores.

Discutir tais valores na teoria da clínica rogeriana pode nos esclarecer melhor para quais direções a nossa atuação tem se encaminhado. Esperamos, com este artigo, poder trazer luz ao papel dos valores do psicólogo em sua atividade na clínica rogeriana, promovendo uma atuação crítica e coerente com a teoria na qual está embasada. Além disto, procuramos, como Rogers (1957/1992), “(...) poder auxiliar os terapeutas a pensar de forma mais crítica sobre os elementos de sua experiência, atitudes e comportamentos que são essenciais para a psicoterapia, aqueles que não são e os que são até mesmo prejudiciais" (p. 176). Desta forma, muito além de trazer respostas, o texto pretende suscitar questões e nos aproximar de temas éticos pertinentes à atuação clínica de modo a encontrar meios sempre atuais de demonstrar o valor incondicional daqueles a quem servimos.

\section{O Processo Valorativo na Abordagem Centrada na Pessoa}

A partir da proposta de Carl Rogers, o processo de valoração, ou seja, a forma como as pessoas passam a valorar uma experiência em detrimento de outras (Rogers, 1967/1991), está intimamente ligado ao funcionamento do organismo e ao desenvolvimento da personalidade. Por organismo, Rogers se referia a um sistema sempre mutante que é o centro de toda experiência vivida pelo indivíduo. Este organismo é locus de simbolizações, pensamentos, emoções, sensações e percepções. Sua interação com o mundo ocorre conforme aquilo que é percebido em seu campo experiencial conforme sua tendência de base de realizar-se, manter-se e aperfeiçoar-se (Rogers, 1951/1974b).

Para Rogers, esse organismo parece encontrar sua dinâmica e funcionamento ideal em uma criança recém-nascida. Ele estudou o desenvolvimento infantil e procurou traçar um modelo saudável para esse processo de formação de valores. Segundo ele, uma criança tem uma perspectiva clara de seus valores, entendendo que valores são decorrentes de uma função organísmica e não simbólica. No caso da criança, ela “(...) prefere experiências que mantém, aumentam ou efetivam o seu organismo, e rejeita as que não servem para essa finalidade" (Rogers, 1967/1991, p. 15-16). A criança valoriza a segurança, o alimento quando está com fome e a nova experiência em si mesma; também desvaloriza a dor, os gostos amargos, sons altos e repentinos, a fome, etc. Rogers concebe que se trata de um processo bastante flexível e variável, 
fortemente vinculado à experiência vivida no momento. Trata-se de um "[...] processo organísmico de valorização, em que cada elemento, a cada momento em que a criança sente, é de algum modo pesado, e selecionado ou rejeitado, e isso depende do fato de, nesse momento, permitir ou não a realização do organismo" (p. 16).

Rogers (1977/2001) também percebeu um processo semelhante de transformação e realização entre os demais seres vivos. Aqui, a tendência atualizante foi considerada como um processo equiparado à vida, não podendo se frustrar aquela sem que houvesse consequências danosas para esta. Sob esta perspectiva, Rogers (1967/1991) tratou de valores objetivos ${ }^{1}$, que se referem a quaisquer organismos vivos, e que são invariantes entre as culturas; sua incidência ocorre quer sejam ou não sentidos ou pensado como desejáveis. Segundo ele (Rogers, 1951/1974b), nos seres humanos o desenvolvimento do organismo ocorre na direção de uma maior realização e autonomia, mas também no sentido de comportamentos mais socialmente aceitáveis.

Rogers (1967/1991) utiliza este modelo de desenvolvimento para falar de valores operativos, também chamados de "organísmicos" que, como o próprio termo indica, estão de acordo com as demandas do organismo e de sua forma de funcionamento. Aqui, os valores referem-se àquilo que o indivíduo percebe como capaz de satisfazer suas necessidades; caso sinta fome, naquele momento, a comida pode ser o seu valor, relativo à sobrevivência.

Podemos também considerar os valores concebidos ou pensados, referindo-se a uma classe que pressupõe uma atividade de simbolização e que se manifesta por antecipação à experiência direta da pessoa. Eles ocorrem por interiorização da experiência de outros:

(...) nessas interiorizações, a pessoa passa a acreditar que os elementos valorativos são seus e não admite certas emoções, sentimentos e sensações da consciência. Então, o organismo, pela função da consciência, fica impedido de examinar e avaliar as próprias experiências, distorcendo-as e se dissociando delas (Castelo Branco, 2010, p. 60).

A fim de sistematizar sua teoria sobre a dinâmica da personalidade, Rogers (1977/2001) parte do princípio de que todo ser humano tem necessidade de amor (aceitação) e se comporta de maneira a viver a experiência de amor. Quando recebe consideração condicional e tem sentimentos ou se comporta de forma que não obtém tal amor das pessoas que lhes são significativas, passa a assimilar que o que é bom e necessário ao seu organismo é mau para aqueles a quem estima. Na expectativa de manter tal amor, ela passa a introjetar este tipo de juízo e, depois, o aceita como seu. Desde então “(...) abando-

\footnotetext{
1 Em sua classificação de valores, Rogers (1967/1991) utiliza-se da divisão estabelecida por Charles Morris.
}

nou a sabedoria de seu organismo, desistindo do centro de avaliação, e está tentando comportar-se de acordo com os valores estabelecidos por outros, a fim de conservar o amor" (Rogers, 1977/2001, p. 18). Tal dinâmica caracterizará toda a formação da subjetividade humana, bem como está na base de processos patológicos que serão abordados a seguir.

\section{A formação do self a partir do processo de valoração}

O eu (self) surge como uma parte do campo de percepção e vai se diferenciando a partir da experiência valorativa que faz do mundo e de si mesmo, sendo seus elementos aquilo que é controlado por ele. Rogers (1951/1974b), explicitando sua teoria genética da personalidade, comenta que a partir da

(...) interação com o ambiente e de modo particular como resultado da interação valorativa com os outros, forma-se a estrutura do ego - um modelo conceptual, organizado, fluido mas consistente de percepções, de características e relações do 'eu' ou de 'mim', juntamente com os valores ligados a esse conceito (p.481).

Apesar de se formar a partir do organismo, destacamos que o eu (self) não se assemelha inteiramente com ele. Na verdade, podem desenvolver-se em direções diametralmente opostas. Castelo Branco (2010) alerta que:

(...) o eu (self) não é sinônimo de organismo (...), e que ele é formado da interação do organismo com o ambiente. Destarte, enquanto o organismo é um sistema total que funciona por leis próprias, o eu (self) é um autoconceito organizado de si que, (sic) pode restringir ou não o funcionamento organísmico (p. 43, grifos do autor).

Ao conceber que o eu (self) surge a partir de uma diferenciação do organismo, Rogers também compreende que a mesma tendência à regulação, à realização e à atualização estão presentes no desenvolvimento egóico. Assim, quando a experiência do eu e do organismo estão congruentes, a tendência atualizante caminha de forma unificada. Porém, quando ocorre um desacordo, a tendência organísmica pode ser contrária à tendência que ocorre no Eu (self) (Rogers, 1951/1974b). Este último caso é razão importante para tudo aquilo que convém chamar de psicopatologia segundo a ACP.

No caso de uma incongruência, Castelo Branco (2010) comenta que ela se deve a uma auto-regulação ideal por conta de uma simbolização distorcida das experiências. Afirma que "(...) essas simbolizações distorcidas negam à consciência certas experiências sentidas diretamente pelo organismo, e ensejam desajustes psicológicos, impedindo uma abertura para a experiência em foco e ini- 
bindo uma abertura para novas experimentações" (p. 45). Em estado de incongruência, frente a uma necessidade iminente e considerando a relação entre organismo e eu (self), o comportamento só ocorre por meios que estejam em coerência com a concepção inconsistente que o eu faz de si mesmo (noção-de-eu). Na maior parte dos casos, dentre as possibilidades de se comportar o indivíduo escolhe aquela que não lhe exige qualquer distorção, intercepção ou negação na simbolização da experiência organísmica. Por outro lado, Rogers (1951/1974b) comenta que a necessidade do organismo pode, após chegar a um ponto de ter sido fortemente negada, provocar comportamentos que ultrapassem esta limitação imposta pela noção do eu. Ocorre nesse caso uma distorção, intercepção ou negação da necessidade ou mesmo de seu comportamento. Estas são situações, dentre outras possíveis, em que a pessoa sente que algo está fora de seu controle ou percebe que as coisas não acontecem como gostaria.

Estando em congruência, é possível considerarmos, segundo Castelo Branco (2010), que o organismo se percebe em auto-regulação real. Nesse caso,

(...) apesar de haver conceitos, valores e percepções introjetados cultural e socialmente, o organismo, com base na consciência, consegue simbolizar essas experiências conforme efetivamente as experimenta em suas emoções, sentimentos, sensações e afetividades. Essa simbolização ocorre no organismo de uma forma congruente e coerente no eu (self) (...) (p.46).

Nesta situação, Rogers comenta que o processo de valoração toma uma nova direção a partir da consciência e daquilo que é simbolizado por ela (Rogers, 1977/2001). O self, a partir de sua experiência com os outros significativos ${ }^{2}$, lança nova luz sobre os sentimentos e os comportamentos do organismo. Nesta relação com os outros significativos, o eu (self) faz uma troca, não necessariamente simbolizada, entre os seus valores e os dos outros, mudando o centro avaliativo da sua experiência e ocorrendo que aquilo que antes satisfaria a pessoa, agora é negado e transformado. Rogers (1977/2001) comenta:

(...) as crenças ou construtos introjetados são rígidos e estáticos porque foram absorvidos de fora. Eles não estão sujeitos ao processo normal da criança de avaliar sua experiência de maneira fluida, dinâmica. (...) Se as condições de valor impostas à criança são numerosas e significativas, então a dissociação pode tornar-se muito grande e as consequências psicológicas, como vimos, realmente muito sérias (p. 278).

\footnotetext{
2 Na primeira socialização, estes outros significativos podem ser os familiares, como o pai, a mãe e os irmãos. Depois, com a chamada segunda socialização, pode-se considerar os grupos sociais em que indivíduo se insere, tais como a escola, os amigos e a religião, entre outros.
}

Assim, a criança surge como vítima das circunstâncias e da educação dos pais, segundo Carl Rogers. Conforme relata na entrevista a Frick (1975), ao sujeito é possível transcender a uma educação repressora, por exemplo, mas isso se torna mais difícil quando está submetido a condições mais severas. Neste caso, apesar de Rogers acreditar que é possível que o sujeito supere esse tipo de educação, ele “(...) encontrará grande dificuldade em rejeitar aquelas condições sem alguma ajuda, alguma espécie de clima terapêutico, quer seja planejado ou não" (Frick, 1975, p. 113). É preciso salientar que o Eu (self) e a consciência não entram nesse processo somente para trazer danos. Sua importância se deve ao fato de serem os intermediários entre as demandas internas e externas, eliminando um possível conflito entre elas (Castelo Branco, 2010). Seria preciso errar tudo de novo, caso não pudéssemos aprender da cultura através do eu (self); ou mesmo não poderíamos falar de desenvolvimento cultural.

Na compreensão de Castelo Branco (2010), Rogers frisava “(...) a importância da restauração do contato com essa experiência organísmica, como fonte para o desenvolvimento de uma maturidade psicológica” (p. 49). No processo psicoterapêutico, então, quando vive tais valores introjetados e suas possíveis incongruências e angústias, o cliente passa a experimentar suas próprias apreciações, seus interesses e desejos e coloca em xeque aquilo que viveu até ali, seguindo-se um período de crise e confusão. Quando suspende aquilo em que se apoiou até então, o cliente mesmo é quem parece estar suspenso e sem bases sobre o que valorar como importante (Rogers, 1951/1974b). A partir de então, através do encontro consigo, inclusive com aspectos que antes havia alienado, em um embate com o outro de si (Vieira \& Pinheiro, 2013), a confusão inicial é "substituída gradualmente pela compreensão nascente de que a evidência sobre o que pode apoiar um juízo de valor lhe é dada pelos próprios sentidos, pela própria experiência” (Rogers, 1951/1974b, p. 156). Neste processo, que é concomitante ao processo de transformação da personalidade, o indivíduo que também vai adquirindo uma concepção de eu (self) mais fluida, a princípio, compreende seus valores de forma fixa e radicada no objeto. $\mathrm{O}$ cliente, em seguida, reconhece que tais valores não precisam ser fixos e que as apreciações podem ser feitas por ele mesmo. A proposta psicoterapêutica é, assim, de uma reaproximação do cliente de sua experiência mais profunda, até mesmo a mais visceral, ou seja, de reaproximar o indivíduo de sua organicidade e dos valores ligados a ela. É este processo de aproximação que possibilita uma mudança de personalidade (reorganização), tal como abordada por Carl Rogers. Ouvindo, então, a si mesma, a pessoa tem mais experiências próprias nas quais pode confiar, o que, segundo Castelo Branco (2010), confere ao indivíduo uma maior espontaneidade assim como uma maior aceitação de seus comportamentos e atitudes. Tal postura 
(...) desencadeará uma mudança (reorganização) de personalidade e de comportamento, possibilitando que as experiências, antes tomadas como ameaçadoras, e os novos experimentos possam ser adequadamente examinadas e simbolizadas à luz do funcionamento organísmico e do eu (self) (p. 47).

Segundo Rogers (1957/1992, 1961/2009) uma reorganização da personalidade em congruência com o organismo ocorre em um ambiente de calor humano, pautado em atitudes de autenticidade, de empatia e de consideração positiva incondicional. Tais atitudes são a base do processo psicoterápico proposto por Rogers, tendo ele se referido a elas como componentes suficientes e fundamentais (Rogers, 1957/1992), que pode ser caracterizado como um processo de aprendizagens significativas de tais atitudes, as quais estão imbuídas de valores, que serão melhor tratados na sessão seguinte.

\section{A ACP como uma prática de valores}

Carl Rogers, mesmo sem perceber de início, desenvolveu uma nova prática no campo da psicologia clínica, cujo princípio norteador é a confiança irrestrita no potencial dos seres humanos para encontrar as melhores respostas diante das situações que lhes são colocadas; seu principal valor é a própria pessoa (Rogers, 1942/1974a). Sua prática segue o pressuposto de que o indivíduo é quem melhor pode responder sobre a situação em que se encontra e, portanto, é ele quem deve guiar o seu próprio tratamento. Estava deslocado, assim, o papel do psicoterapeuta, que deve, então, ser especialista em não ser especialista (Schmid, 1999).

Na busca de sempre promover a pessoa do cliente, o próprio papel do psicólogo rogeriano assumiu diversas posições. A pessoa do psicoterapeuta foi valorada de formas diferentes ao longo do desenvolvimento da proposta de Carl Rogers. Trata-se de um caminho no qual a pessoa do profissional vai se tornando cada vez mais importante ao longo do processo. Assim, é possível perceber, no início do trabalho de Rogers (1942/1974a), um cuidado consigo mesmo, quase uma vigilância, para que o psicólogo não interviesse com seus sentimentos no processo do cliente. Ele deveria ser neutro. Tal postura foi confundida com uma atitude de laissez-faire (Rogers, 1951/1974b), “(...) quando na verdade o esforço de Rogers era no sentido de desconstruir a figura de autoridade do terapeuta" (Moreira, 2010, p. 539). Em seguida, o papel do psicoterapeuta entra em uma fase em que a "não-diretividade" é substituída pela noção de "centramento no cliente", a partir da qual o psicólogo passou a refletir os sentimentos do cliente. Neste período, o terapeuta deve fomentar o desenvolvimento do cliente, oferecendo uma atmosfera de segurança; e é aqui que Rogers (1957/1992) desenvolve as atitudes facilitadoras. Mais à frente, outro momento importante para a formação desse lugar do terapeuta dentro do processo clínico centrado na pessoa foi a fase conhecida como experiencial (Cury, 1987). Nela, a partir da influência de Eugene Gendlin (1970), passou a dar maior importância não só à experiência do cliente, mas também do psicoterapeuta e entre ambos. O objetivo psicoterapêutico era promover o contato do cliente com a sua experiência de forma plena. Esse momento foi caracterizado também pela "descoberta" das obras de Buber e Kierkegaard, chegando a considerar este último como um amigo sensível e altamente perceptivo (Rogers, 1961/2009) Moreira (2010) destaca que

(...) aqui é enfatizada a autenticidade do terapeuta enquanto atitude facilitadora. $\mathrm{O}$ psicoterapeuta deve confiar em seus próprios sentimentos, sendo congruente com a própria experiência; ou seja, a sua experiência passa a ser entendida como parte da relação terapeuta-cliente. É nesse sentido que a relação deixa de ser entendida como centrada no cliente, para ser compreendida como bicentrada, visto que consiste em um esforço para explorar dois mundos fenomênicos, fazendo-os interatuar em benefício do cliente através da criação de novos significados a partir do espaço experienciado por ambos (p. 540).

Além disto, o profissional, como ser humano, passou a assumir um papel importante, não pelas técnicas utilizadas, mas principalmente por suas atitudes, sentimentos e expressões; todo o método submete-se a um sistema de valores daquilo que viria a se transformar na Abordagem Centrada na Pessoa e, por consequência, do psicólogo rogeriano:

(...) pode-se dizer, de uma forma mais adequada, que o conselheiro em ação na terapia centrada no paciente assume um conjunto coerente e evolutivo de atitudes profundamente radicadas na sua organização pessoal, um sistema de atitudes que recorre a técnicas e a métodos coerentes dentro desse sistema (Rogers, 1951/1974b, p. 33-34).

Como uma ciência social e historicamente determinada, a proposta de Rogers (1961/2009) tomou, assim, valores de sua sociedade e de seu momento histórico. Entre suas influências e valores adquiridos, podemos considerar seus estudos na área da Agricultura e em Teologia, bem como sua formação cristã. Além disto, é preciso citar a sociedade estadunidense, com seu pragmatismo, seu otimismo mesmo após as guerras mundiais, a psicanálise e as ciências do comportamento desenvolvidas ali, entre outras. Já temos alguns trabalhos ${ }^{3}$ (Moreira, 2007; Freire, 1989, 2002) que lidam com essas influências na obra de Rogers. O trabalho de Moreira (2007) apresenta

\footnotetext{
3 Por não querermos repetir a temática de tais estudos, optamos por trabalhar minimamente tais influências em nosso artigo.
} 
a noção de pessoa como fortemente vinculada à cultura dos Estados Unidos, bem como a uma tradição cristã. Tal vínculo ofereceu limites à teoria de Rogers, dentre os quais, ela considera, uma compreensão de homem alienada das questões sociais. Além disso, a partir dos estudos de Freire (2002), Vieira \& Pinheiro (2013) recentemente nos apontaram como Rogers valorou, em sua obra, os momentos de harmonia e de unidade em detrimento dos momentos de crises, de estranhamento e tensão. Em seu artigo, os autores analisam como Rogers procurou "conduzir" o cliente a um domínio sobre a sua condição, evitando tensões mais duradouras e fomentando a compreensão de uma realidade a ser conquistada, completamente simbolizada pelo eu.

\section{As técnicas e os valores}

Não há técnicas, a priori, na abordagem centrada na pessoa, mas atitudes que promovem o valor da pessoa humana como ser singular. Desta forma, qualquer atitude que o psicólogo tomar deve estar vinculada a seu sistema de valores; do contrário, corre o risco de obter somente resultados parciais (Rogers, 1951/1974b, p. 34). Rogers reaproximou a ciência daquilo que era eminentemente humano, pois "sua contribuição não foi tecnológica, mas ética: ele não trouxe meios novos e sim fins novos. Mudança de paradigma” (Amatuzzi, 2010, p. 13). Importa, agora, a formação do psicólogo (pelo menos, o rogeriano), não somente em termos técnicos ou conceituais, mas, também, na direção de um desenvolvimento de valores apropriados à prática centrada na pessoa. É importante destacar que o tempo de formação de um "conselheiro" competente está diretamente relacionado ao grau de aproximação que ele tem com os valores humanistas. Por conta de tal importância é que muitos cursos e workshops da abordagem centrada na pessoa utilizam um método que enfatiza uma aprendizagem não só teórica, mas, também, vivencial e significativa, que pretende promover um conhecimento que diga respeito a toda a vida dos sujeitos envolvidos. Destacamos, ainda, a importância dos estágios em clínica psicológica oferecidos pelos cursos de formação e da experiência profissional para uma melhor apropriação desses valores, haja vista que não são poucos os relatos de alunos e novos profissionais que vivem na tensão entre usar atitudes facilitadoras como uma técnica e tê-las como um valor. Rogers (1951/1974b) comentava que esta dificuldade está relacionada principalmente com a pouca experiência que os estagiários e profissionais recém-formados têm com os princípios da perspectiva escolhida.

Ainda que, a princípio, Rogers (1951/1974b) tenha optado pelo uso de técnicas para fundamentar a abordagem, nesta perspectiva a técnica assume um lugar secundário e abre espaço para uma relação de "pessoa para pessoa”, a ponto de afirmar que a técnica pode, até mesmo, ser prejudicial no encontro entre psicoterapeuta e cliente (Rogers, 1957/1992). Até mesmo quando escreveu seu livro "Terapia Centrada no Paciente” (Rogers, 1951/1974b), diante da possibilidade de ele ser lido somente como um manual sobre psicoterapia, Rogers chegou a afirmar que preferia que tal produção nunca tivesse existido, acreditando que o processo psicoterapêutico não deveria se resumir ao uso de técnicas. O trabalho do psicólogo é, portanto, oferecer um ambiente propício para o desenvolvimento pessoal de seu paciente, em um lugar onde seja possível conhecer-se em seu potencial e em seus limites. Ao profissional, cabe propiciar uma relação humana calorosa na qual as duas pessoas possam estar inteiras no encontro, o que é proporcionado pelas atitudes facilitadoras. Para tanto, ele mesmo deve cuidar de estar completo na relação, não só como prestador de serviços de psicologia, mas como um ser humano em relação com outro. Assim, entra em cena um profissional que, também, é uma pessoa, que tem uma história, que vive alegrias e tristezas, que tem uma visão de mundo - ainda que seja aquela oferecida pela abordagem ou ciência que adotou -, que tem sentimentos, percepções e valores, pois assim é o ser humano, não uma consciência apartada do mundo, mas, sempre em contato, projetando-se nele e sendo com ele.

A promoção e facilitação do desenvolvimento pessoal do cliente ocorre por meio de atitudes que Rogers (1957/1992) considerou serem necessárias e suficientes para a transformação da personalidade. Tais atitudes, conforme apontado anteriormente, estão imbuídas de valores e serão melhor tratadas a seguir.

\section{A autenticidade}

Ser genuíno pressupõe valorizar a própria experiência e ouvir-se no seu próprio íntimo, daí porque Amatuzzi (1989) considera que a genuinidade “(...) é antes operativa do que concebida” (p. 97); a vivência de tal atitude não deve ser parcial, mas deve referir-se à pessoa por inteiro, sendo seu principal impedimento um conceito de eu rígido. Ela não deve ser somente uma técnica, uma ação preconcebida, conceitual, meramente racional, mas uma disposição, um valor. Cabe perguntar se qualquer valor significativo experimentado pelo psicólogo dever participar de sua comunicação no encontro psicoterapêutico com o cliente; ou se sua genuinidade pode pôr em risco a congruência experiencial de seu cliente. Cabe, por exemplo, ao profissional, posicionar-se sobre a intenção suicida de seus clientes ou sobre a sua sexualidade, lançando, sobre a pessoa, argumentações e sugestões pautadas na própria experiência e nos valores do psicólogo?

A atitude de autenticidade é uma disposição que, também, tem como valores a relação e a consideração da singularidade dos seres que estão envolvidos nela (Gobbi, 
Missel, Justo \& Holanda, 2005), quer seja a do psicoterapeuta, quer a do cliente. Corroborando o princípio de que a autenticidade não é somente um valor para consigo mesmo, mas para com outrem, também, Amatuzzi (2010) defende que ela está fundamentada no valor da "harmonia das partes no todo pessoal" (p. 22). Segundo ele, esta atitude refere-se à honestidade, na qual não se deve sonegar nenhuma informação relevante à relação. Para Vieira \& Pinheiro (2013) a autenticidade, por não ser da ordem do estático, mas do devir, é também, uma oportunidade para que o encontro psicoterapêutico seja também um embate com a alteridade, com o estranho, com aquilo que não se pode abarcar. Para ele, a psicoterapia não é somente um encontro com o mesmo, com a identidade, mas, justamente por ser uma relação autêntica, é também um processo de deparar-se com o outro verdadeiramente outro, com a dimensão alteritária. Vieira \& Freire (2006) explicitam:

No que se refere à autenticidade, esta não nos parece uma atitude cognitiva, onde o cliente e o terapeuta totalizariam suas respectivas experiências sensíveis. De fato, tratar-se-ia de uma vulnerabilidade ao excesso que ultrapassa a palavra pronunciada por qualquer um destes, afetação pelo que não pode nem deve ser explicado (p. 429-430).

A psicoterapia, por ser um lugar de promoção do ser autêntico, deve, de igual modo, ser uma experiência de estranhamento, tanto quando um momento de reconhecimento, haja vista que o ser está em transformação contínua.

\section{A consideração positiva incondicional}

Tal atitude fundamenta-se na valoração do indivíduo como ser digno de confiança e respeito. Para Amatuzzi (2010), ela está firmada sobre o valor do amor e favorece a unidade, a procura por associar-se ao outro. Por outra via, Vieira \& Pinheiro (2006), ao fazer aproximações com a ética da alteridade radical de Lévinas (2008), apontam a consideração positiva incondicional como uma responsabilidade para com o Outro, a quem não poderemos nunca determinar, totalizar ou diagnosticar. A consideração positiva incondicional significa o reconhecimento de sua singularidade, que, como alteridade, vai além de nós e, portanto, não cabe avaliá-la segundo nossos padrões, sendo tal postura uma tentativa de tornar o Outro um "mesmo" e, desta forma, uma desconsideração da experiência do cliente: "a escuta de uma singularidade trazida pelo cliente e uma diferença que não pode ser violentada por qualquer saber anterior à relação terapêutica" (Vieira \& Pinheiro, 2006, p. 429). Não se trata, assim, de uma situação de busca de unidade, mas de reconhecimento da alteridade, que, também, nos constitui, mas que nos extrapola.

\section{A empatia}

Considerar a alteridade é abrir-se para ela, procurar "ouvi-la" com todos os sentidos e acolhê-la com portas e janelas abertas (Freire, 2002). A consideração positiva deve impelir o profissional a uma tentativa de escutar melhor o cliente; o valor do cliente convoca o psicoterapeuta a oferecer uma escuta qualificada, procurando perceber seu campo fenomenológico e compreendendo-o sem distorções, o máximo possível. A empatia, além de estar relacionada à consideração positiva incondicional, também se alia à autenticidade, de modo que o psicólogo procure ouvir-se e perceber com que lentes olha para o cliente, para assim, poder colocá-las de lado, a fim de melhor compreender a forma como o cliente percebe a si mesmo. Do contrário, não ouve a pessoa, mas somente aquilo que quer ouvir, as confirmações das teorias e de (pre)conceitos já estabelecidos, mesmo que não estivessem conscientes. Para Rogers (1983):

Essa atitude pode ser muito sutil, e é surpreendente perceber quanto posso ser habilidoso nisso. Basta que eu torça suas palavras um pouquinho, que eu distorça ligeiramente seu significado, e parecerá não somente que ele está dizendo o que quero ouvir, mas também que é a pessoa que eu quero que ele seja (p. 8).

Segundo Amatuzzi (2010), tal atitude aponta para o valor da sabedoria organísmica, em detrimento da ciência; para ele, a compreensão empática promove um conhecimento que está para além da cognição, criando a possibilidade de uma relação com o "conhecido" que não seja o da totalização ou do fechamento na racionalidade. Esse tipo de conhecimento, portanto, encontra-se também na ignorância, por não querer saber tudo (Vieira, 2009).

\section{Os valores do psicólogo rogeriano e sua atuação na clínica}

Entendemos que a prática rogeriana trata de um exercício de valores e que, além disso, propicia uma aprendizagem de valores, mas que por se tratarem de valores organísmicos e, portanto, experienciais, não devem se referir somente à experiência do profissional rogeriano, mas encaixarem-se e transformarem-se de acordo com a experiência também vivida pelo cliente, quer na relação com o psicólogo ou não.

É possível, assim, que o psicólogo rogeriano tenha valores totalmente diferentes daqueles assumidos pelo cliente, mas entendemos que a prática clínica é lugar de centramento na pessoa do cliente, ou mesmo lugar de descentramento (Vieira \& Pinheiro, 2013), onde urge o desenvolvimento pessoal. Portanto, apesar de possíveis diferenças de valores, dentro de uma relação terapêutica deve-se optar por valores que promovam uma 
relação autêntica, onde são consideradas a ambos, psicoterapeuta e cliente, em um relacionamento de pessoa para pessoa.

O trabalho de Rogers (1961/2009) se reporta a um tipo de indivíduo, promotor de uma subjetividade, de uma forma de ser. Rogers parecia ter a esperança de alcançar, a partir de seu fazer psicológico, a transformação da sociedade, promovendo indivíduos com valores tais como os elencados na sessão anterior de nosso trabalho (harmonia, alteridade, unidade, responsabilidade, amor e sabedoria). Nos últimos anos de seu trabalho, Rogers promoveu seu pensamento mais como um estilo de vida do que como uma abordagem ou corrente de pensamento psicológico. Ele repudiava a forma como a ciência de sua época estava transformando os indivíduos, procurando controlá-los cada vez mais. Em psicoterapia, caracterizando-a como um processo de auxílio à pessoa em sofrimento psicológico e entendendo que tal sofrimento é devido a uma discrepância entre o processo de valoração organísmica e aquele vivido pelo self, o trabalho do psicólogo rogeriano consiste, também, em promover aprendizagens significativas na forma como as pessoas valoram as diferentes situações e relações que estabelecem em suas vidas. O próprio Rogers cita a transformação de valores como uma das principais vias de desenvolvimento pessoal no processo psicoterapêutico. Entendemos, desta forma, que a abordagem centrada na pessoa constitui-se na formação e transformação de valores, promovendo uma valoração que esteja mais de acordo com o próprio organismo.

Quando tratamos de ensino-aprendizagem de valores, por sua vez, não nos referimos a eles tais como são concebidos na maior parte das escolas, nas quais os professores são detentores do conhecimento e devem repassar tais conteúdos aos alunos, que têm pouco interesse neles. Referimo-nos ao processo indicado por Carl Rogers (1969/1975) e denominado de ensino centrado no aluno ou de aprendizagem significativa.

\section{Convergências e divergências entre os valores da abordagem centrada na pessoa e os dos profissio- nais rogerianos}

Com referência à incidência dos valores pessoais na prática clínica dos psicólogos rogerianos, destacamos o trabalho de Graziottin (2009) que procurou investigar quais as qualidades éticas inerentes à teoria e à prática da ACP. Em sua pesquisa, trabalhou com psicólogos da Europa e da América do Norte e utilizou entrevistas em que os profissionais comentavam sobre situações em que se encontraram em dilemas éticos, relacionando-os a seus valores e crenças, e, também, aos da ACP. Graziottin (2009) comenta que os psicólogos entrevistados apontaram convergências e divergências entre as duas classes de valores. Eles citaram a confiança e o respeito pela na- tureza humana, a autonomia e a autodeterminação como valores fundamentais da ACP, mas, entre os valores de sua prática psicológica rogeriana, também citaram o valor da vida como fundamental. Este valor, entretanto, foi referido como sendo terciário no que se refere à teoria da abordagem centrada na pessoa. Mostra-se claramente uma situação em que os valores pessoais do psicólogo rogeriano influenciam sua prática psicológica. A escolha do valor da vida como fundamental na prática psicológica foi expressa a partir do discurso de que nem sempre o cliente está apto a tomar a decisão de suicidar-se; nessa ocasião, o profissional, em prol do cliente, deveria intervir na sua atitude, "salvando" sua vida. Uma psicóloga informante disse: "Sou completamente de acordo com isso [não interferir na forma como outra pessoa vive]. Exceto sob certas circunstâncias, então meu valor, meu valor pela vida é o valor maior.” (p.47).

Por outro lado, quando se refere ao valor pela vida na da abordagem centrada na pessoa, a mesma entrevistada comenta que "(...) você valoriza a vida e a qualidade de vida como uma parte da Abordagem Centrada no Cliente. Eu acho, mas eu não penso que a ética da ACP realmente envolva salvar vidas" (Graziottin, 2009, p. 61). Eis aqui um detalhe importante, pois a confiança no indivíduo pede que a consideração positiva seja incondicional, isto é, em qualquer ocasião. Ainda que Carl Rogers (1951/1974b) acredite que, se forem dadas as condições facilitadoras, em meio à ideação suicida o cliente optará por continuar vivendo. $\mathrm{O}$ posicionamento de Rogers parte da autonomia do paciente para tomar tal decisão, pois ele afirma:

A mim parece-me que apenas na medida em que o terapeuta desejar completamente que possa ser escolhido qualquer resultado, qualquer direção - ele compreenderá a força vital da capacidade e potencialidade do indivíduo para uma ação construtiva. É na medida em que ele deseja que a morte possa ser a escolha, que a vida é escolhida; que a neurose possa ser a escolha, que é escolhida a normalidade saudável (p. 61).

A proposta de Rogers, assim, parece levar às últimas consequências o valor que atribui ao indivíduo, promovendo sua autonomia em relação ao psicólogo. Por outro lado, aqui, aprece-nos um nó górdio, que requer atenção, mas que, por conta dos limites de nosso artigo, haverá de ser tratado em outro momento: apesar de entender que o psicólogo não deve interferir na autonomia do cliente, ele parece, na teoria de Rogers, estar subjugado a um "determinismo" do organismo que lhe exige uma escolha pela vida. A liberdade apregoada pela ACP está, então, subjugada a uma ordem natural, quase um instinto pela vida Frick (1975), ao entrevistar Carl Rogers, em 1969, expressou melhor esta questão, à qual Rogers respondeu afirmativamente: 
(...) se as condições são maduras ou adequadas para o organismo humano, parece-me depreender-se a idéia de que o homem fará automaticamente aquelas coisas boas na vida como parte de sua natureza inerente. Quer dizer, o homem não escolhe, realmente, entre bem e mal. É governado por uma espécie de piloto automático se as condições forem boas (p. 110).

Perguntamo-nos, todavia: ao apontar momentos em que o cliente não pode tomar uma decisão sem a intervenção do profissional, volta-se, novamente, o centro da psicoterapia para a "cura" ou para a figura do psicólogo? Eis, aqui, mais uma possível divergência entre valores apontada na pesquisa. Percebemos, ainda, que grande parte dos valores elencados pelos profissionais de alguma forma se relacionam com aqueles abordados no início de nosso texto, ou seja, são também tidos como valores pessoais, indicando que a prática da ACP refere-se, assim, à apropriação de seus princípios por seus seguidores.

O trabalho do psicólogo rogeriano, em todo caso, é demonstrar, ao máximo possível, o valor e o apreço que o profissional tem pela pessoa à sua frente. Como Rogers (1957/1992) destaca, diante da dificuldade do cliente de percebê-los, o profissional procura, sempre, por novas formas de expressá-los, e, quem sabe, até técnicas que melhor possam expressar ao paciente o valor que vê nele. Além do mais, acreditamos, juntamente com Graziottin (2009), que tais divergências de valores referem-se à experiência, mas não apenas a ela, visto que estas dificuldades se apresentam mesmo em psicólogos com maior tempo de prática. A escassez de textos sobre as condutas éticas da prática clínica da abordagem centrada na pessoa revela que este tema não tem sido devidamente apropriado pelos profissionais rogerianos.

\section{Considerações finais}

Ao longo de nosso trabalho, tratamos da abordagem centrada na pessoa, que destaca, como seu principal valor, o ser humano. Enfocamos os aspectos clínicos dos valores subjacentes à ACP. Estudamos não somente este valor principal, mas, também aqueles valores secundários e terciários, como o valor da própria experiência, da harmonia, da alteridade, da unidade e da sabedoria organísmica.

Pudemos verificar e apontar que a prática da abordagem centrada na pessoa está estabelecida sobre valores que embasam, desde o seu modo de pensar e de fazer ciência, até a sua proposta de atuação, envolvendo as atitudes facilitadoras, bem como a atividade clínica como um todo. Destacamos que, justamente por se fundamentar em valores, a prática da ACP não se justifica para além deles e não falar é possível tratar das atitudes do psicólogo rogeriano somente como uma aplicação de técnicas, mas como a efetivação de valores que se referem à experiência do profissional. Portanto, enfatizamos a importância do cuidado com a formação dos psicólogos da ACP com vistas não apenas ao conhecimento da teoria ou a aplicação de suas propostas, mas que, também, contemple seus valores. Estar disposto a trabalhar com a abordagem centrada na pessoa é lidar com seus valores e considerá-los como próprios, não por meio de uma introjeção, fruto de um ensino centrado na figura do "mestre", mas de uma aprendizagem significativa e crítica.

A partir daquilo que discutimos, pensamos que, apesar da experiência com a prática clínica ser um fator importante para a assimilação dos valores da abordagem centrada na pessoa, mesmo psicólogos experientes podem experimentar dificuldade com tais valores e com as atitudes facilitadores diante de alguns dilemas éticos. Assim, apontamos a necessidade de momentos de discussão e de produção de conhecimento nos quais possamos tratar da aplicação da ética da abordagem centrada na pessoa em situações-limite. Isto é evidenciado, principalmente, pela escassez de produções referentes à ACP e à dificuldade de debater sobre a teoria e prática desta em encontros de profissionais da área.

Indicamos que a psicoterapia deve ser considerada como uma experiência de aprendizagem centrada no cliente-aprendiz, em detrimento de um ensino centrado na figura do psicólogo-mestre. Nesta perspectiva, os valores são desenvolvidos e assumidos a partir de uma reaproximação das experiências organísmicas que fazem sentido para o cliente, não cabendo, assim, ao profissional, embutir seus valores nas situações vividas pelo cliente. Apontamos, aqui, uma atuação que não se paute somente em uma das atitudes, como a autenticidade, por exemplo, mas que encare a atividade clínica a partir da consonância das três atitudes referidas neste artigo, mesmo que com intensidades diferentes e de acordo com a situação. O exercício de tais atitudes promove um ambiente em que o psicólogo possa ser ele mesmo sem que, para tanto, interfira na consideração que tem pelo cliente.

Finalmente, há questões que continuam a nos inquietar, mas acreditamos que elas poderão tornar-se pontos de partida para novas pesquisas. Percebemos que, por tratar de processos centrados no organismo, Rogers (1951/1974b) indica situações em que o indivíduo parece não poder escolher ou a sua escolha parece ser falsa, haja vista que ele está submetido às determinações do organismo. Entendemos, entretanto, que tal argumento parece contradizer o valor principal da abordagem centrada na pessoa, ou seja, a autonomia do sujeito, por ela tão enfatizada. Esperamos que nosso trabalho possa contribuir para incitar novos temas nos encontros de profissionais da ACP e novas produções em que seja contemplado o exercício de valores na sua prática, até mesmo para além da clínica. 


\section{Referências}

Amatuzzi, M. M. (1989). O resgate da fala autêntica: filosofia da psicoterapia e da educação. Campinas: Papirus.

Amatuzzi, M. M. (2010). Rogers: Ética humanista e psicoterapia. Campinas: Alínea.

Castelo Branco, P. C. (2010). A noção de organismo no fieri teórico de Carl Rogers: uma investigação epistemológica. Dissertação de Mestrado em Psicologia. Universidade Federal do Ceará. Fortaleza.

Cury, V. E. (1987). Psicoterapia centrada na pessoa: evoluções das formulações sobre a relação terapeuta-cliente. Dissertação de Mestrado em Psicologia Clínica. Universidade de São Paulo. São Paulo.

Freire, J. C. (1989). A ética da psicologia centrada na pessoa em Carl Rogers. Dissertação de Mestrado em Educação. Universidade Federal do Ceará. Fortaleza.

Freire, J. C. (2002). O lugar do outro a modernidade tardia. São Paulo: Annablume.

Frick, W. B. (1975). Psicologia Humanista: Entrevistas com Maslow, Murphy e Rogers. Rio de Janeiro: Zahar.

Gendlin, E. (1970). A theory of personality change. In J. Hart \& T. Tomlinson (Eds.), New directions in client-centered therapy (pp. 129-173). Boston: Houghton Mifflin.

Gobbi, S. L.; Missel, S. T.; Justo, H. \& Holanda, A. (2005). Vocabulário e Noções Básicas da Abordagem Centrada na Pessoa. São Paulo: Vetor Editora.

Graziottin, T. (2009). The ethics of the Person-Centred Approach. Dissertação de Mestrado em Psicoterapia [Counseling]). University of Strathclyde. Glasgow.

Lévinas, E. (2008). Totalidade e Infinito. Lisboa: Edições 70.

Moreira, V. (2007). De Carl Rogers a Merleau-Ponty: a pessoa mundana em psicoterapia. São Paulo: AnnaBlume.

Moreira, V. (2009). Clínica Humanista-Fenomenológica: estudos e em psicoterapia e psicopatologia crítica. São Paulo: Annablume.

Moreira, V. (2010). Revisitando as fases da abordagem centrada na pessoa. Estudos de Psicologia (Campinas), 27(4), 537-544.

Rogers, C. R. (1974a). Psicoterapia e consulta psicológica. São Paulo: Martins Fontes. (Originalmente publicado em 1942).

Rogers, C. R. (1974b). Terapia centrada no paciente. $2^{\text {a }}$. ed. Lisboa: Moraes Editores. (Originalmente publicado em 1951).

Rogers, C. R. (1975). Liberdade para aprender. Belo Horizonte: Inter Livros. (Originalmente publicado em 1969).

Rogers, C. R. (1983). Um jeito de ser. São Paulo: EPU.

Rogers, C. R. (1992). The Necessary and Sufficient Conditions of Therapeutic Personality Change. Journal of Consulting Psychology. 60(6), 199-203.
Rogers, C. R. (2001). Sobre o poder pessoal. 4ª ed. São Paulo: Martins Fontes. (Originalmente publicado em 1977)

Rogers, C. R. (1991) (Org.) De pessoa para pessoa: o problema de ser humano. $4^{\mathrm{a}}$. ed. São Paulo: Pioneira (Originalmente publicado em 1967).

Rogers, C. R. (2008). Carl Rogers Dialogues. Revista da Abordagem Gestáltica, 14(1), 21-27.

Rogers, C. R. (2009). Tornar-se Pessoa. São Paulo: Editora WMF Martins Fontes.

Kinget, G. M. (1977). O Terapeuta. Em C. R. Rogers \& G. M. Kinget (Orgs.). Psicoterapia e relações humanas: teoria e prática da terapia não-diretiva (Vol. 1, pp. 101-115). Belo Horizonte: Interlivros (Original publicado em 1965).

Schmid, P. F. (2000) 'Encountering a human being means being kept alive by an enigma' (E. Levinas). Prospects on further developments in the Person-Centered Approach. In J. Marques-Teixeira \& S. Antunes, S. (Org.) Client-Centered and Experiential Psychotherapy. Linda a Velha: Vale \& Vale. pp. 11-33.

Vieira, E. M. (2009). Sobre a proposta de conhecimento presente na teoria Rogeriana, ou da sabedoria residente na ignorância. Revista do NUFEN (UFPA), 1(2), p. 4-19.

Vieira, E. M. \& Freire, J. C. (2006). Alteridade e Psicologia Humanista: uma leitura ética da Abordagem Centrada na Pessoa. Estudos de Psicologia (Campinas), 23(4), 425-432.

Vieira, E. M. \& Pinheiro, F. P. H. A. (2013). Person centered psychotherapy: an encounter with oneself or a confrontation with the other? Estudos de Psicologia (Campinas), v.30, n.2, p. 231-238.

Iago Cavalcante Araújo - Psicólogo e Mestrando do Programa de Pós-Graduação em Psicologia da Universidade Federal do Ceará. Bolsista da Fundação Cearense de Apoio ao Desenvolvimento Científico e Tecnológico (FUNCAP). Endereço Institucional: (Departamento de Psicologia) Av. da Universidade, 2762 - Benfica, Fortaleza-CE. 60020180. Brasil.E-mail: iago@ymail.com

José Célio Freire - Doutor em Psicologia e Docente do Programa de Pós-Graduação em Psicologia da Universidade Federal do Ceará. E-mail: jcfreire@ufc.br

Recebido em 28.03.2013 Primeira Decisão Editorial em 17.08.13 Segunda Decisão Editorial em 23.09.13 Aceito em 26.04.14 